\title{
EXTRACTION OF SCATTERED SMALL-SCALE LANDSLIDES DISTRIBUTION BY OBJECT-BASED CLASSIFICATION USING OPTICAL HIGH-RESOLUTION SATELLITE IMAGES
}

\author{
H. Hashiba ${ }^{1}$, M. Sonobe ${ }^{1}$ \\ ${ }^{1}$ Department of Civil Engineering, College of Science and Technology, Nihon University, Japan \\ (hashiba.hideki, sonobe.masashi)@nihon-u.ac.jp
}

KEY WORDS: Land slide, Superpixel segmentation, SLIC, SLICO, Object-based classification, high-resolution image

\begin{abstract}
:
Continuous heavy rain for a long duration over mountainous terrain, where the elevation is relatively low and the topography is complex leads to multiple small-scale landslides over a wide area. Detailed investigations of small-scale landslides have been effectively carried out using optical high-resolution satellite images with spatial resolution of about $2 \mathrm{~m}$ or less. In this study, the sediment-related disaster caused by heavy rain in northern Kyushu, Japan that occurred in July 2017 was selected as a typical example of small-scale landslide. For this landslide event, the applicability of the conventional superpixel segmentation for landslide separation was examined. The applicability of the representative SLIC and SLICO methods in the superpixel segmentation method by image interpretation in the case of a large number of small-scale landslides in a wide area was assessed. These results suggest that in the case of such a disaster, segmentation by the SLICO method will be better. In addition, the set value of the area size for the area division was systematically examined from the distribution tendency of the average NDVI value in the divided area. It was shown that the landslide region can be extracted with relatively high accuracy by the land cover classification process by the NN method by using the appropriate region size examined by the SLICO method.
\end{abstract}

\section{INTRODUCTION}

In recent years sediment-related disasters caused by heavy rainfall over a wide area have occurred frequently in Japan. Continuous heavy rain for a long duration over mountainous terrain, where the elevation is relatively low and the topography is complex leads to multiple small-scale landslides over a wide area. In the event of such a landslide-related disaster, it is necessary to investigate the location of the landslide in detail for rapid rescue operations and smooth restoration of social infrastructure. Detailed investigations of small-scale landslides have been effectively carried out using optical high-resolution satellite images with spatial resolution of about $2 \mathrm{~m}$ or less. In addition, land cover can usually be classified with relatively high accuracy by applying object-based classification to highresolution satellite images. As a segmentation method for object-based classification, the SLIC (Simple Liner Iterative Clustering) and the SLICO (Zero parameter version of SLIC) have been widely applied so far (Achanta et al., 2012). In addition, the effects of various methods are comparatively studied (Chen and Ming, 2019; Crommelinck et al., 2017; Li and Chen, 2015). On the other hand, to extract landslides, object-based classification by various methods has been mainly studied for medium resolution satellite images (Dabiri et al., 2019a; Dabiri et al., 2019b). In addition, some effects of objectbased classification on landslide extraction using high resolution satellite images have been investigated (Helno et al., 2016; Hölbling et al., 2015; Lu et al., 2011; Martha et al., 2011; Martha and Kerl, 2010). Recently, object-based classification has been applied to landslide observation images by UAV (Jiao et al., 2018; Karantanellis et al., 2019; Rau et al, 2011). While many studies have investigated large-scale landslides using object-based classification, this method has seldom been applied for extracting the distribution of small-scale landslides that frequently occur in mountainous regions with complex terrain. In particular, there is a lack of comparative studies on the applicability of the conventional methods for the segmentation of scattered, small-scale landslides and setting appropriate values of regional scale parameters for segmentation. In this study, the sediment-related disaster caused by heavy rain in northern Kyushu, Japan that occurred in July 2017 was selected as a typical example of small-scale landslide. For this landslide event, the applicability of the SLICO and SLIC methods that are conventional superpixel segmentation methods for landslide separation was examined. Consequently, using the most appropriate segmentation area identified from this study, the extractability of the landslide area by objectoriented land cover classification was evaluated.

\section{DATA USED AND ANALYTICAL METHODS}

\subsection{Study area}

The mountainous landscape around Asakura City, Fukuoka Prefecture was selected as the study area. The area includes many small streams and rivers and is prone to small-scale landslides. The widespread landslides caused by heavy rain in July 2017 occurred in this region. The test area was identified a $2 \mathrm{~km} \times 2 \mathrm{~km}$ focal area for investigation (Figure 1).

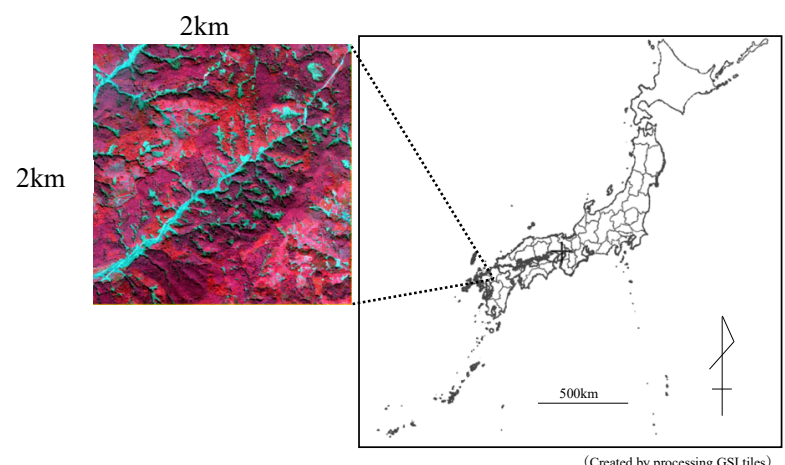

Figure 1. Test area 


\subsection{Imagery data}

Two 8-band multispectral images of the $2 \mathrm{~km} \times 2 \mathrm{~km}$ focal area were used for analysis: (a) for May 11, 2017 before the disaster and (b) for September 13, 2017 after the disaster (Figure 2). These were sourced from the Worldview-2 satellite with a spatial resolution of $2 \mathrm{~m} \times 2 \mathrm{~m}$. The image data were converted to ground surface reflectance and then ortho-processed. For land cover classification, data sets with 1-8 band images before and after the disaster, which were strictly superimposed by orthorectification were created. For landslide segmentation, image data of bands 1-8 after the disaster were used. In the subsequent land cover classification processing, all image data of bands 1-8 before and after the disaster were used. The occurrence of several small-scale landslides were confirmed by visual interpretation of the images.

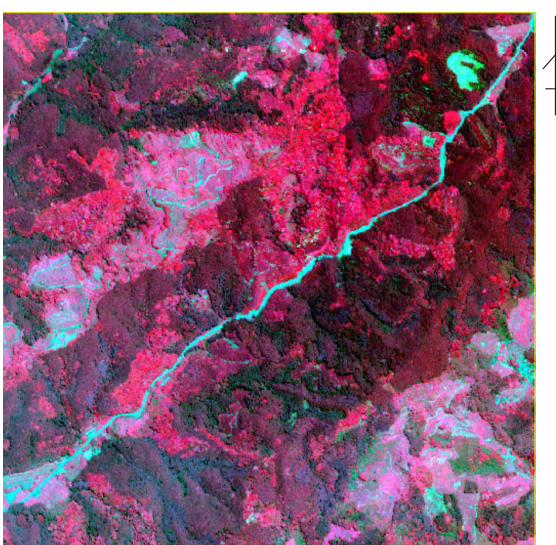

(a)Before disaster (Acquisition date: May 11, 2017)

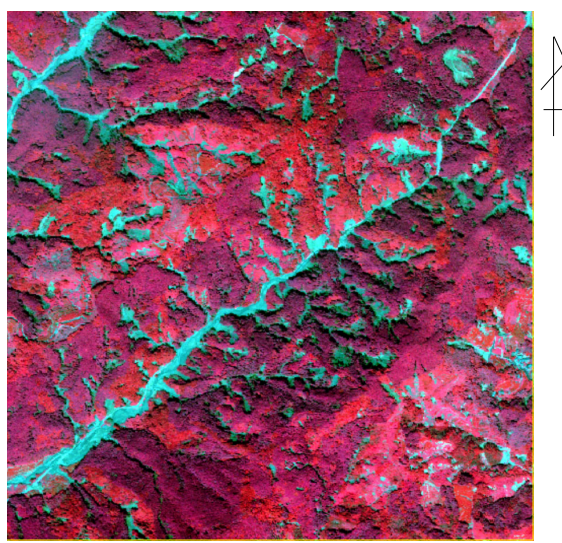

(b)After disaster (Acquisition date: September 13, 2017)

Figure 2. The false color image in test area $(2 \mathrm{~km} \times 2 \mathrm{~km})$

\subsection{Segmentation process}

The comparative performance of two segmentation methods namely the SLIC (Simple Liner Iterative Clustering) and the SLICO (Zero parameter version of SLIC) were assessed for segmenting landslides using post-disaster images. The eCognition Developer ${ }^{\circledR}$ was used for segmentation of the landslide area and subsequent classification (Trimble, 2017). Three $300 \mathrm{~m} \times 300 \mathrm{~m}$ segmentation evaluation areas were identified in the study area, as shown in Figure 3(a), and in each area, the segmentation method was compared and examined. In each test area, the area size parameter for dividing the area was systematically set from 2 to 32 for both methods, and the landslide area division property from image interpretation was compared. Subsequently, an appropriate area size for segmentation was quantitatively evaluated by the method determined to be well-divided. This was evaluated using average NDVI value within each segment. The degree of division of each segment according to the land cover type is affected by the relative proportion of area under trees and bare ground, indicating landslides. To evaluate this, the degree of coexistence of forests and bare ground (i.e., landslides) was extracted from the change tendency of the average NDVI value in the segment due to the change in the area size parameter. From the results, the largest area size parameter that adequately separated the forest and bare ground was identified.

\subsection{Land cover classification}

Land cover was classified using nearest neighbor classification (NN) method from the multi-band image data in the segmented images, before and after the disaster. The segmentation method that provided more appropriate results between the two was applied. In addition, it was identified based on the appropriate scale parameters considered for region division. The following classification categories: landslide 1; landslide 2; shade occurring at the boundary between landslide and forest; forest 1 ; forest 2; river sandbar and river water surface were set. Landslide 1 and the landslide 2 were approximately classified based on the difference in the display of colors on the image by the image interpretation of the bare ground, indicating the landslide in the image interpretation. Similarly, forest 1 and the forest 2 were broadly classified as per the difference in color display on the image of the forest surface. The reference data for classification were sampled by image interpretation on the segmented image.

\subsection{Accuracy evaluation}

In the test area, a small area that was used for evaluating classification accuracy was selected (Figure 3(b)). In order to create an evaluation standard for classification accuracy, preprocessing was performed on the images to improve the image interpretation after the disaster. The classification reference data were created through discrimination by interpretation on an image obtained by resampling the original image of $2 \mathrm{~m} \times 2 \mathrm{~m}$ resolution using the cubic convolution method to three times the original resolution. Additionally, accuracy evaluation by superimposing the classification results by the $\mathrm{NN}$ method rearranged using resampling process according to the pixel size was performed. The size of the area considered for accuracy evaluation on the image after the resampling process was 1000 pixels $\times 1000$ pixels i.e., $335 \mathrm{~m} \times$ $335 \mathrm{~m}$ when converted to local distance. The classification results were compared with the created reference data, and accuracy was evaluated by confusion matrix for the classification criteria.

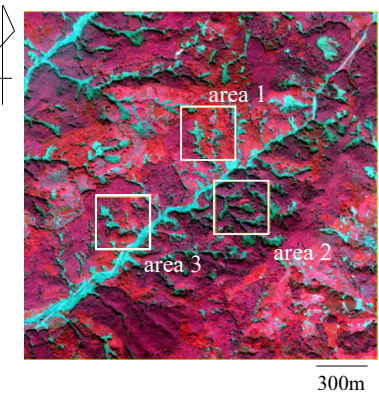

(a)Test area for Segmentation

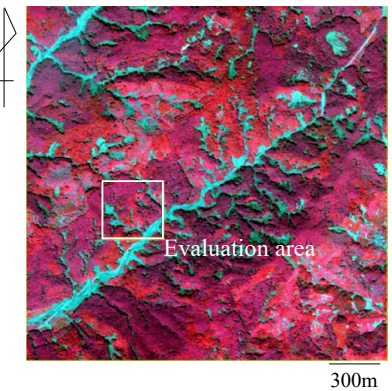

(b) Test area for evaluation of classification accuracy
Figure 3. Verification area for segmentation and classification accuracy 


\section{RESULTS AND DISCUSSION}

\subsection{Comparison of segmentation methods}

The comparison of segmentation with the SLIC and SLICO methods at the three locations is shown in Figure 4-6. Different scale parameters were applied and compared for the SLIC method and the SLICO method in three test areas. In order to examine the effect of segmentation by image interpretation, three types of region sizes for segmentation were set: 4,8 , and 16. With the SLIC method, the region tended to be relatively rectangularly divided. If the region size is 4 , the landslide surface tends to be divided to some extent by small rectangular segments. However, as the region size became larger, the rectangular characteristics of the segment tended to be more emphasized. Furthermore, the tendency that multiple land covers such as landslide surface and forest surface coexist in the rectangle became stronger. As a result, the outer edge shape of the landslide surface, which is complex and distributed on a small scale, tended to be insufficiently divided. In contrast, with the SLICO method it was possible to divide the landslide more accurately by changing the area according to the outer edge shape of the landslide that varies in different directions. When the region size was 4 to 8 , it was recognized that the complicated shape of the fine landslide surface could be well separated. However, at the region size of 16 , the degree of mixture of land cover within the segment tended to increase. Thus, it was considered that effective results can be obtained by applying an appropriate region size. Hence, it was concluded that the SLICO method can be used to divide the area more appropriately when multiple small-scale landslides occur on a complex terrain.

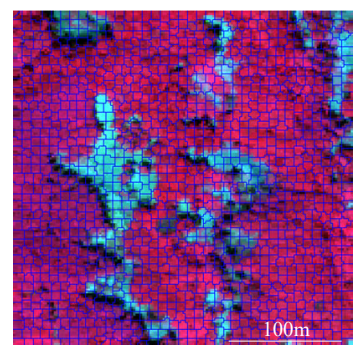

(a) SLIC (region size:4)

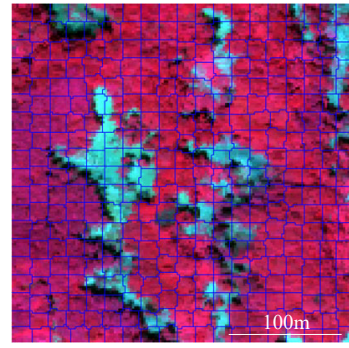

(c) SLIC (region size:8)

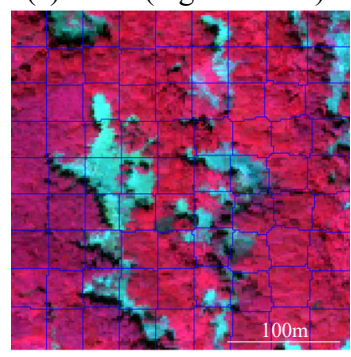

(e) SLIC (region size:16)
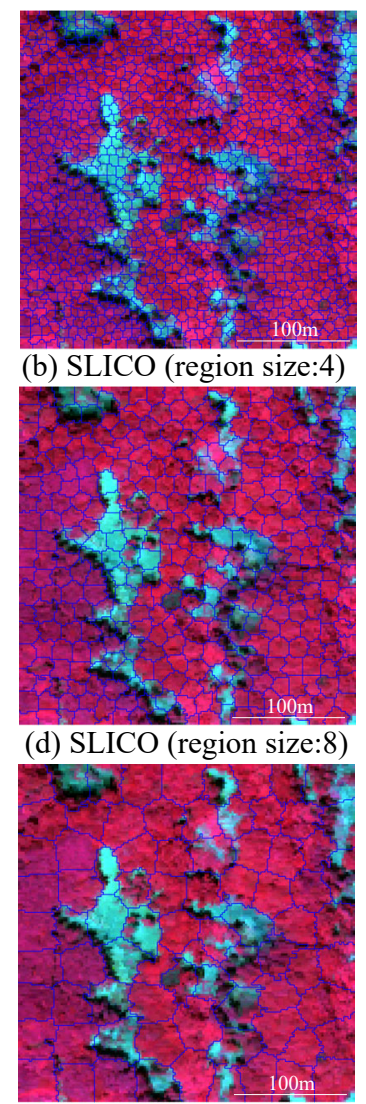

(f) SLICO (region size:16)

Figure 4. Comparison of segmentation in area 1
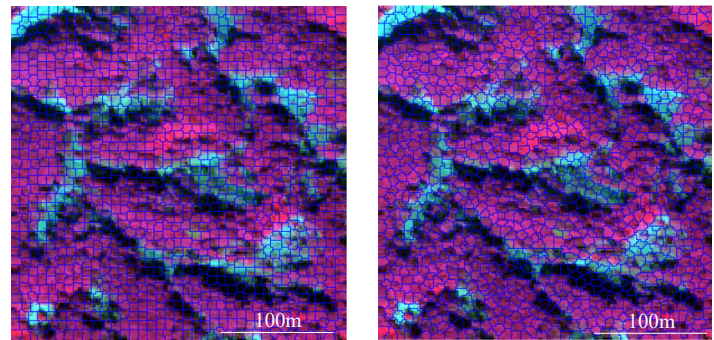

(a) SLIC (region size:4)

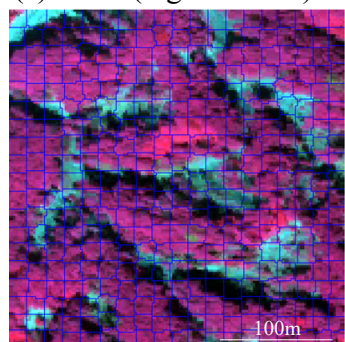

(c) SLIC (region size:8)
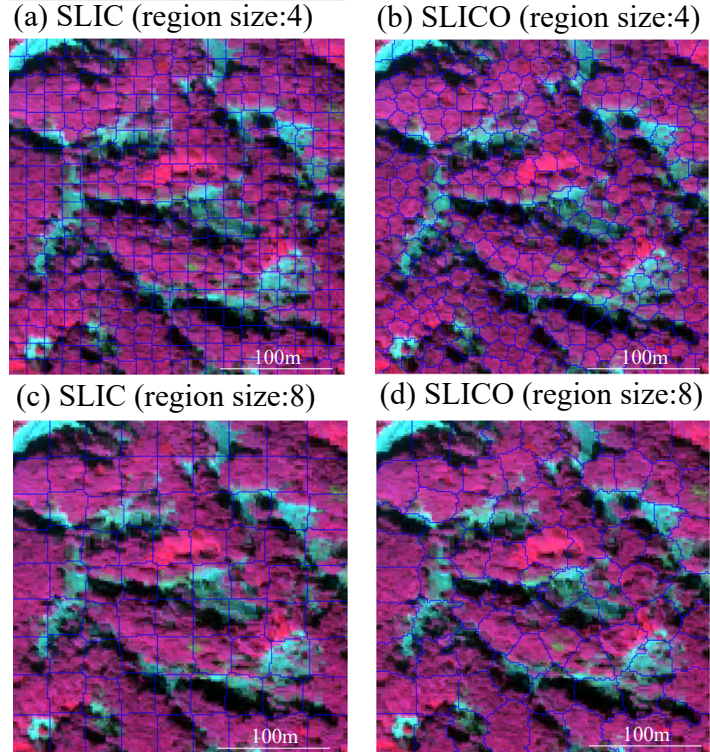

(d) SLICO (region size:8)

(e) SLIC (region size:16)

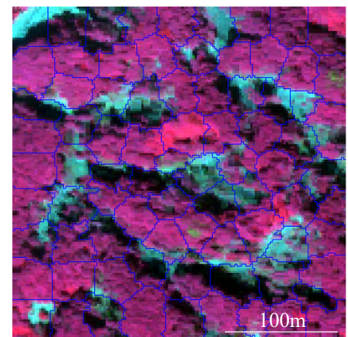

(f) SLICO (region size:16)

Figure 5. Comparison of segmentation in area 2
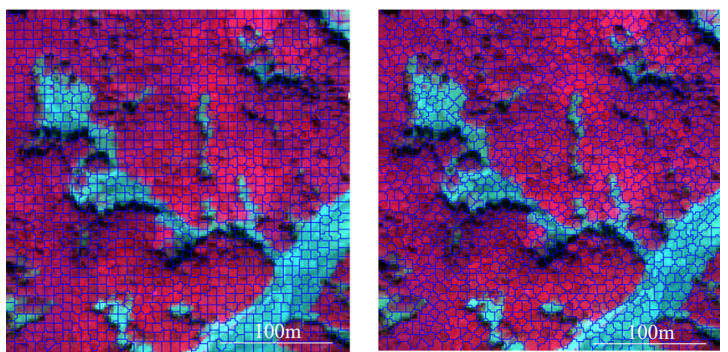

(a) SLIC (region size:4)
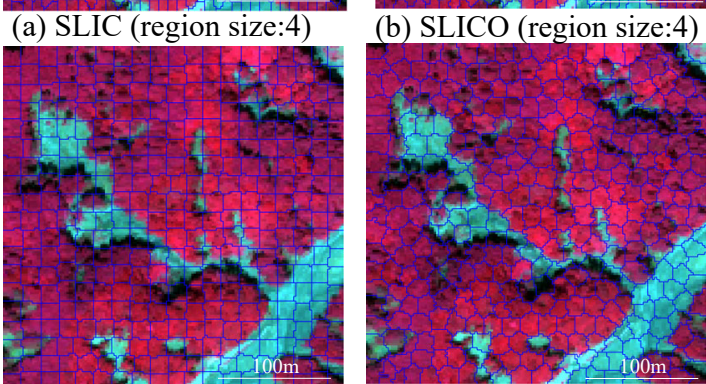

(c) SLIC (region size:8)

(d) SLICO (region size:8)
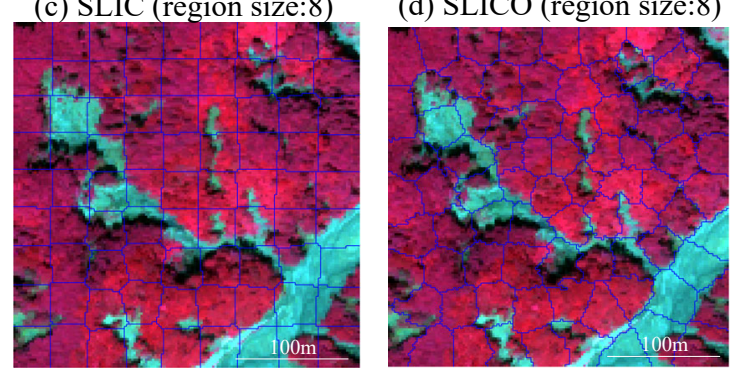

(e) SLIC (region size:16)

(f) SLICO (region size:16)

Figure 6. Comparison of segmentation in area 3 


\subsection{Scale parameter of segmentation}

In the area size where the landslide and the forest were almost properly divided, when the whole of the divided area was filled with forest, the average NDVI value in the area was approximately $0.6-0.8$. In contrast, when the area was filled with landslides, the tendency was approximately $0-0.3$. Furthermore, when the forest and the landslide could not be divided sufficiently and the shadow area caused by the landslide was included in the divided area, intermediate range values of approximately $0.3-0.6$ were observed. From these results, the appropriate area size for dividing the landslide was evaluated from the change in the distribution tendency of the average NDVI value in each area when the area size was changed (Figure 7). When the area size was below about 8, no significant change was observed in the distribution of the average NDVI value of $0.6-0.8$ indicating forest. Moreover, when the area size was in the range 5-8 the ratio of the intermediate NDVI value when forest and landslide areas were mixed tended to gradually increase with area size. In contrast, the ratio of the average NDVI value of $0-0.3$ indicating bare ground tended to decrease gradually. In addition, when the area size was in the range $2-5$, the ratio of each of the three average NDVI distribution regions did not change significantly. Consequently, in this study, when the area size was 8 or less, the tendency that each land cover species was divided relatively well was evaluated. When classifying land cover using the $\mathrm{NN}$ method, setting the area size as 5 (wherein no large change was detected in the ratio of each distribution area of the average NDVI value) produced highly accurate classification results.

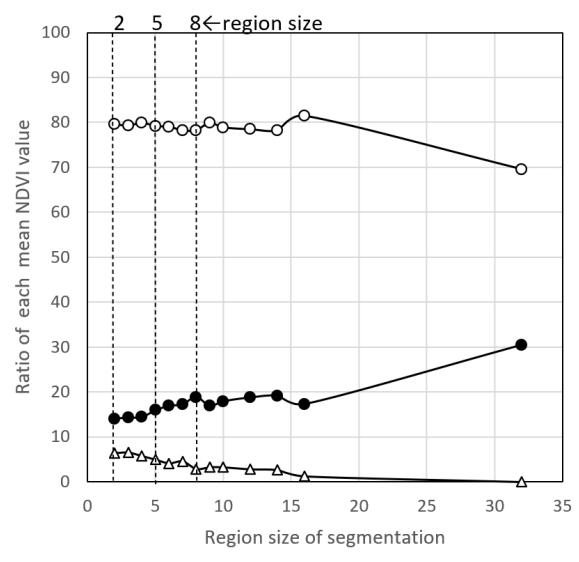

Class of mean NDVI: $\rightarrow \longrightarrow 0 \sim 0.30 \longrightarrow 0.35 \sim 0.55 \longrightarrow 0-0.60 \sim 1.00$

(a) Case of area

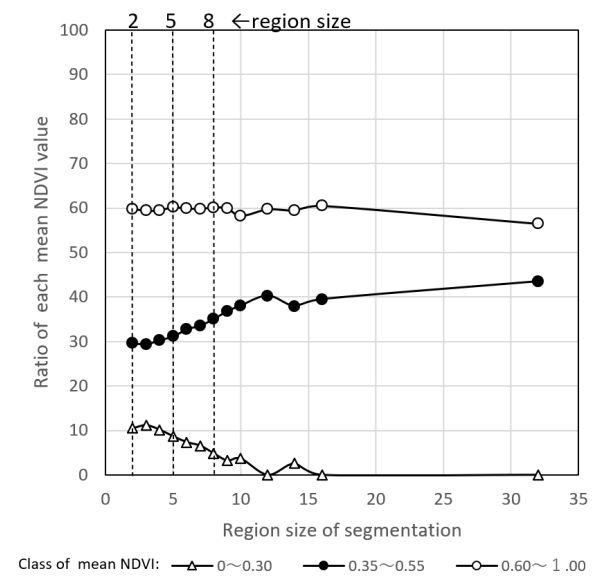

(b) Case of area 2

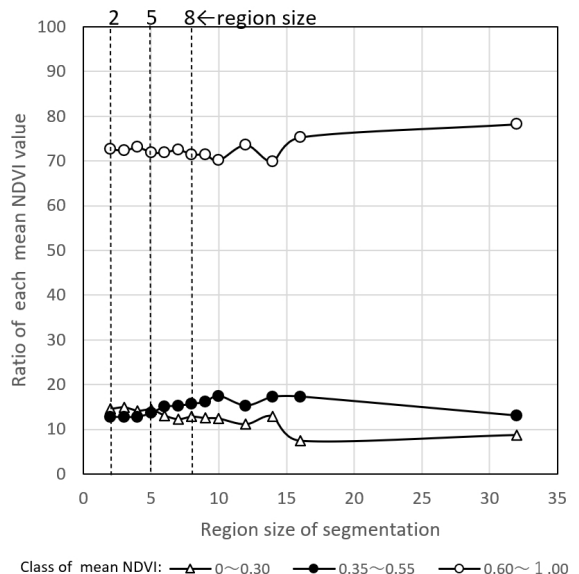

(c) Case of area 3

Figure 7. The change in the distribution tendency of the average NDVI value within each segment as region size changes

\subsection{Classification results}

The extraction of the landslide area by object-oriented land cover classification using the setting method of the evaluated segmentation was examined. For segmentation with the SLICO method, the area size was set to 5 based on the systematic examination results, and the area was segmented using the predisaster image. The classification results are shown in Figure 8. Many small-scale landslides were extracted well and tended to be well-separated from river sandbars. In this evaluation, the area under landslides was 14\%.

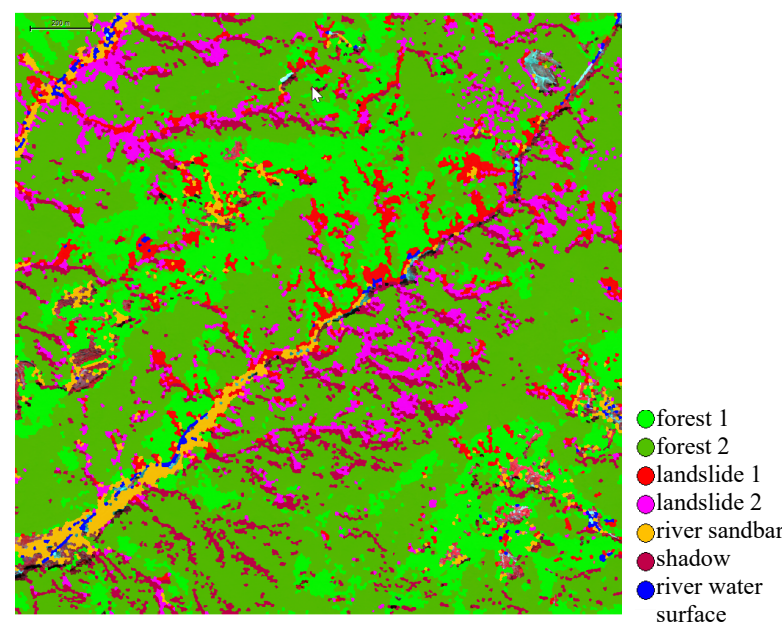

Figure 8 . The result of classification by $\mathrm{NN}$ method (segmentation method: SLICO, region size: 5)

The post-disaster image in the classification accuracy evaluation area, corresponding reference data, and the classification results are presented in Figure 9. In this case, the categories forest 1 and forest 2 were merged and evaluated as forest. Similarly, landslide 1 and landslide 2 were merged into a single category landslide. Furthermore, as river water surface had very few classified pixels it was included in the others category. The result of accuracy evaluation is shown in Table 1 and Table 2 . The overall classification accuracy obtained was 0.90 ; the average of producer's accuracy was 0.83 , and the average of user's accuracy was 0.79 . Considering only the landslide classification category, producer's accuracy was 0.75 and user's 
accuracy was 0.74 . In addition, when the shadow generated at the boundary between the landslide and the forest was evaluated as a landslide area, the overall accuracy increased by approximately $2 \%$, whereas the average producer's and user's accuracy increased by approximately $3-7 \%$. The producer's and user's accuracy of only landslide increased by approximately 3 $8 \%$. The shade area generated at the boundary between the forest and bare land caused by the landslide varied with the direction of the slope where the disaster occurred. Therefore, it was difficult to scrutinize the location of landslide occurrence individually. However, as the shadow area generated after the disaster was presumed to be caused by the landslide, it is considered appropriate to include the classification result of the shadow area in the landslide when estimating the area value of the landslide surface. Furthermore, even if the shadow area were not considered to be due to landslide, the obtained results are practically helpful for prompt disaster response by rapidly identifying the landslide locations, as field survey investigation is difficult immediately after the disaster. Thus, it was concluded that small-scale landslide distribution can be effectively extracted by object-based classification from highresolution satellite images and can contribute to prompt disaster response.

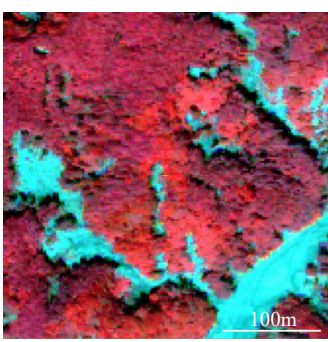

(a)Original image for interpretation

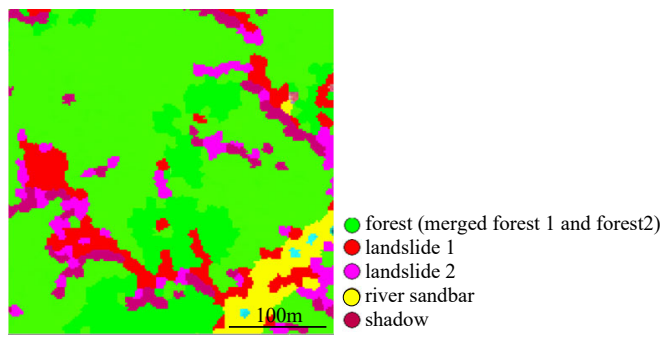

(c) Evaluation data based on classification results

Figure 9. Verification of classification accuracy in the evaluation area

\begin{tabular}{|c|c|c|c|}
\hline Case of categories & $\begin{array}{c}\text { Average of Producer's } \\
\text { Accuracy }\end{array}$ & $\begin{array}{c}\text { Average of User's } \\
\text { Accuracy }\end{array}$ & Overrall Accuracy \\
\hline A & 0.83 & 0.79 & 0.90 \\
\hline B & 0.86 & 0.86 & 0.92 \\
\hline
\end{tabular}

A: 5 categories

$B:$ When shadow is merged with landslide

Table 1. Evaluation of classification accuracy

\begin{tabular}{|c|c|c|}
\hline Case of categories & Producer's Accuracy & User's Accuracy \\
\hline A & 0.75 & 0.74 \\
\hline B & 0.83 & 0.77 \\
\hline
\end{tabular}

A: Land slide in case of 5 categories

B: Land slide when shadow is merged with landslide

Table 2. Evaluation of classification accuracy of landslide classification categories

\section{CONCLUTION}

In this study, the extraction of small-scale landslides caused by torrential rain in northern Kyushu by object-based classification using high-resolution satellite images obtained before and after the disaster was examined. The applicability of the representative SLIC and SLICO methods in the superpixel segmentation method by image interpretation in the case of a large number of small-scale landslides in a wide area was assessed. These results suggest that in the case of such a disaster, segmentation by the SLICO method will be better. In addition, the set value of the area size for the area division was systematically examined from the distribution tendency of the average NDVI value in the divided area. Using the SLICO method the region was relatively divided well when the region size was below 8 , and a tendency of greater stability was noticed when the region size was $2-5$. These results suggest that the land cover was classified with relatively high accuracy by the classification processing in the area size five by the SLICO in the NN method. In future, we propose to identify more appropriate segmentation methods and evaluate the validity of the setting parameters by adding verification examples from other similar disasters. In addition, a broader review of other segmentation techniques will help in assessing their applicability.

\section{ACKNOWLEDGEMENTS}

The Worldview-2 images used in this study include copyrighted material of MAXAR, Digital Globe, Inc., All Rights Reserved.

\section{REFERENCES}

Achanta, R., Shaji, A., Smith, K., Lucchi, A., Fua, P., Susstrunk S., 2012: SLIC Superpixels Compared to State-of-the-Art Superpixel Methods. IEEE transactions on pattern analysis and machine intelligence., 34(11), 2274-2282, doi.org:10.1109/ TPAMI.2012.120.

Chen, Y., Ming, D., 2019: Superpixel classification of high spatial resolution remote sensing image based on multi-scale $\mathrm{CNN}$ and scale parameter estimation. Int. Arch. Photogramm. Remote Sens. Spatial Inf. Sci., XLII-2/W13, 681-685, doi.org/ 10.5194/isprs-archives-XLII-2-W13-681-2019.

Crommelinck, S., Bennett, R., Gerke, M., Koeva, M.N., Yang, M.Y., Vosselman, G., 2017: SLIC superpixels for object delineation from UAV data. ISPRS Annals of the Photogramm. Remote Sens. Spatial Inf. Sci., IV-2/W3, 9-16. doi.org/10.5194/ isprs-annals-IV-2-W3-9-2017.

Dabiri, Z., Hölbling, D., Abad, L., Prasicek, G., Argentin, A.-L., Tsai, T.-T., 2019: An object-based approach for monitoring the evolution of landslide-dammed lakes and detecting triggering landslides in TAIWAN. Int. Arch. Photogramm. Remote Sens. Spatial Inf. Sci., XLII-3/W8, 103-108, doi.org/10.5194/isprsarchives-XLII-3-W8-103-2019.

Dabiri, Z., Hölbling, D., Abad, L., Tiede, D., 2019: Assessment of landslide-induced morphology changes using an object-based image analysis approach: a case study of HÍTARDALUR, ICELAND. Int. Arch. Photogramm. Remote Sens. Spatial Inf. Sci., XLII-3/W8, 109-114, doi.org/10.5194/isprs-archivesXLII-3-W8-109-2019. 
Li, Z., Chen, J., 2015: Superpixel segmentation using Linear Spectral Clustering. 2015 IEEE Conference on Computer Vision and Pattern Recognition (CVPR).,1356-1363. doi.org/10.1109/ CVPR.2015.7298741.

Heleno, S., Matias, M., Pina, P., Sousa, AJ., 2016: Semiautomated object-based classification of rain-induced landslides with VHR multispectral images on Madeira Island. Natural Hazards and Earth System Sciences., Vol.16. 10351048. doi.org/10.5194/nhess-16-1035-2016.

Hölbling, D., Friedl, B., Eisank, C., 2015: An object-based approach for semi-automated landslide change detection and attribution of changes to landslide classes in northern Taiwan. Earth Sci Inform., 8, 327-335, doi.org/10.1007/s12145-0150217-3.

Jiao, Q. S., Luo, Y., Shen, W. H., Li, Q., Wang, X., 2018: Rapid extraction of landslide and spatial distribution analysis after JIUZHAIGOU Ms7.0 earthquake based on UAV images. Int. Arch. Photogramm. Remote Sens. Spatial Inf. Sci., XLII-3, 685690. doi.org/10.5194/isprs-archives-XLII-3-685-2018.

Karantanellis, E., Marinos, V., Vassilakis, E., 2019: 3D hazard analysis and object-based characterization of landslide motion mechanism using UAV imagery. Int. Arch. Photogramm. Remote Sens. Spatial Inf. Sci., XLII-2/W13, 425-430. doi.org/10.5194/isprs-archives-XLII-2-W13-425-2019.

Lu, P., Stumpf, A., Kerle, N., Casagli, N., 2011: ObjectOriented Change Detection for Landslide Rapid Mapping. Geoscience and Remote Sensing Letters, IEEE., 8. 701-705. doi.org/10.1109/LGRS.2010.2101045.

Martha, T.R., Kerle, N., 2010: Segment optimisation for objectbased landslide detection. Int. Arch. Photogramm. Remote Sens. Spatial Inf. Sci., XXXVIII-4/C7, GEOBIA 2010: Geographic Object-Based Image Analysis.1-6.

Martha, T.R., Kerle, N., Westen, C.J., Jetten, V., Kumar, K.V., 2011: Segment Optimization and Data-Driven Thresholding for Knowledge-Based Landslide Detection by Object-Based Image Analysis. IEEE Transactions on Geoscience and Remote Sensing, 49(12), 4928-4943. doi.org/10.1109/TGRS.2011.

2151866 .

Rau, J.Y., Jhan, J.P., Lo, C.F., Lin, Y.S., 2011: Landslide mapping using imagery acquired by a fixed-wing UAV. Int. Arch. Photogramm. Remote Sens. Spatial Inf. Sci., XXXVIII1/C22, 195-200.

Trimble Germany GmbH, 2017: eCognition Developer 9.3 Reference Book. Trimble Documentation, Imprint and version 9.3.0. 